\title{
Representation of nucleation mode microphysics in a global aerosol model with sectional microphysics
}

\author{
Y. H. Lee ${ }^{1}$, J. R. Pierce ${ }^{4,5}$, and P. J. Adams ${ }^{2,3}$ \\ ${ }^{1}$ NASA Goddard Institute for Space Studies, and Center for Climate Systems Research, Columbia University, \\ New York, NY, USA \\ ${ }^{2}$ Department of Civil and Environmental Engineering, Carnegie Mellon University, Pittsburgh, PA, USA \\ ${ }^{3}$ Department of Engineering and Public Policy, Carnegie Mellon University, Pittsburgh, PA, USA \\ ${ }^{4}$ Department of Atmospheric Science, Colorado State University, Fort Collins, CO, USA \\ ${ }^{5}$ Department of Physics and Atmospheric Science, Dalhousie University, Halifax, Nova Scotia, Canada \\ Correspondence to: Y. H. Lee (yunha.lee@ nasa.gov)
}

Received: 16 December 2012 - Published in Geosci. Model Dev. Discuss.: 7 February 2013

Revised: 6 June 2013 - Accepted: 18 June 2013 - Published: 13 August 2013

\begin{abstract}
In models, nucleation mode $\left(1 \mathrm{~nm}<D_{\mathrm{p}}<10 \mathrm{~nm}\right)$ particle microphysics can be represented explicitly with aerosol microphysical processes or can be parameterized to obtain the growth and survival of nuclei to the model's lower size boundary. This study investigates how the representation of nucleation mode microphysics impacts aerosol number predictions in the TwO-Moment Aerosol Sectional (TOMAS) aerosol microphysics model running with the GISS GCM II-prime by varying its lowest diameter boundary: $1 \mathrm{~nm}, 3 \mathrm{~nm}$, and $10 \mathrm{~nm}$. The model with the $1 \mathrm{~nm}$ boundary simulates the nucleation mode particles with fully resolved microphysical processes, while the model with the $10 \mathrm{~nm}$ and $3 \mathrm{~nm}$ boundaries uses a nucleation mode dynamics parameterization to account for the growth of nucleated particles to $10 \mathrm{~nm}$ and $3 \mathrm{~nm}$, respectively. We also investigate the impact of the time step for aerosol microphysical processes (a $10 \mathrm{~min}$ versus a $1 \mathrm{~h}$ time step) to aerosol number predictions in the TOMAS models with explicit dynamics for the nucleation mode particles (i.e., $3 \mathrm{~nm}$ and $1 \mathrm{~nm}$ boundary). The model with the explicit microphysics (i.e., $1 \mathrm{~nm}$ boundary) with the $10 \mathrm{~min}$ time step is used as a numerical benchmark simulation to estimate biases caused by varying the lower size cutoff and the time step. Different representations of the nucleation mode have a significant effect on the formation rate of particles larger than $10 \mathrm{~nm}$ from nucleated particles $\left(J_{10}\right)$ and the burdens and lifetimes of ultrafinemode $\left(10 \mathrm{~nm} \leq D_{\mathrm{p}} \leq 70 \mathrm{~nm}\right)$ particles but have less impact on the burdens and lifetimes of $\mathrm{CCN}$-sized particles. The models using parameterized microphysics (i.e., $10 \mathrm{~nm}$ and
\end{abstract}

$3 \mathrm{~nm}$ boundaries) result in higher $J_{10}$ and shorter coagulation lifetimes of ultrafine-mode particles than the model with explicit dynamics (i.e., $1 \mathrm{~nm}$ boundary). The spatial distributions of $\mathrm{CN} 10\left(D_{\mathrm{p}} \geq 10 \mathrm{~nm}\right)$ and $\mathrm{CCN}(0.2 \%)$ (i.e., $\mathrm{CCN}$ concentrations at $0.2 \%$ supersaturation) are moderately affected, especially CN10 predictions above $\sim 700 \mathrm{hPa}$ where nucleation contributes most strongly to $\mathrm{CN} 10$ concentrations. The lowermost-layer CN10 is substantially improved with the $3 \mathrm{~nm}$ boundary (compared to $10 \mathrm{~nm}$ ) in most areas. The overprediction in $\mathrm{CN} 10$ with the $3 \mathrm{~nm}$ and $10 \mathrm{~nm}$ boundaries can be explained by the overprediction of $J_{10}$ or $J_{3}$ with the parameterized microphysics, possibly due to the instantaneous growth rate assumption in the survival and growth parameterization. The errors in $\mathrm{CN} 10$ predictions are sensitive to the choice of the lower size boundary but not to the choice of the time step applied to the microphysical processes. The spatial distribution of $\mathrm{CCN}(0.2 \%)$ with the $3 \mathrm{~nm}$ boundary is almost identical to that with the $1 \mathrm{~nm}$ boundary, but that with the $10 \mathrm{~nm}$ boundary can differ more than $10-40 \%$ in some areas. We found that the deviation in the $10 \mathrm{~nm}$ simulations is partly due to the longer time step (i.e., $1 \mathrm{~h}$ time step used in the $10 \mathrm{~nm}$ simulations compared to 10 min time step used in the benchmark simulations), but, even with the same time step, the $10 \mathrm{~nm}$ cutoff showed noticeably higher errors than the $3 \mathrm{~nm}$ cutoff. In conclusion, we generally recommend using a lower diameter boundary of $3 \mathrm{~nm}$ for studies focused on aerosol indirect effects but down to $1 \mathrm{~nm}$ boundary for studies focused on $\mathrm{CN} 10$ predictions or nucleation. 


\section{Introduction}

Atmospheric aerosols perturb Earth's energy balance by scattering and absorbing solar radiation, known as the aerosol direct effect, and modifying cloud microphysical properties by acting as cloud condensation nuclei (CCN), known as the aerosol indirect effect. The impact of anthropogenic aerosols on global radiative fluxes is significant but highly uncertain due to the aerosol indirect effect, which is the most uncertain of anthropogenic climate forcings. One of the uncertainties in the estimates of the aerosol indirect effect stems from challenges in predicting global distributions of $\mathrm{CCN}$. At a fixed supersaturation, the ability of a particle to act as a $\mathrm{CCN}$ is determined by the particle size and chemical composition and is described relatively well by Köhler theory (Seinfeld and Pandis, 1998). The large uncertainty in CCN prediction is mostly from the estimates of particle number concentrations at $\mathrm{CCN}$ sizes. Atmospheric particles, including $\mathrm{CCN}$-sized particles, can be emitted directly from sources (i.e., primary emission) or can be formed through the microphysical growth of nucleated particles (the formation of $\sim 1 \mathrm{~nm}$ particles from condensable vapors). Uncertainty in these source rates can contribute to large uncertainties in $\mathrm{CCN}$ prediction (Pierce and Adams, 2009c).

Regarding nucleation, there are several widely suggested theories: binary $\left(\mathrm{H}_{2} \mathrm{O}-\mathrm{H}_{2} \mathrm{SO}_{4}\right)$ nucleation, ternary $\left(\mathrm{H}_{2} \mathrm{O}\right.$ $\mathrm{H}_{2} \mathrm{SO}_{4}-\mathrm{NH}_{3}$ ) nucleation, and ion-induced nucleation (Napari et al., 2002; Vehkamaki et al., 2002; Yu et al., 2008). In these theories, $\mathrm{H}_{2} \mathrm{SO}_{4}, \mathrm{NH}_{3}, \mathrm{H}_{2} \mathrm{O}$ and molecular ions cluster together, and when they reach a cluster diameter around $1 \mathrm{~nm}$, they become stable and will not evaporate (Kulmala et al., 2004). The rates at which these stable $\sim 1 \mathrm{~nm}$ particles are formed vary by orders of magnitude between different nucleation theories and parameterizations under the same conditions (Kulmala et al., 2004). Uncertainty in the nucleation rates can contribute to large uncertainties in $\mathrm{CCN}$ prediction if the growth of nucleated particles to $\mathrm{CCN}$ sizes is significant. Several studies have investigated the sensitivity of $\mathrm{CCN}$ predictions to nucleation rates (Kristjánsson et al., 2008; Makkonen et al., 2009; Merikanto et al., 2009; Pierce and Adams, 2009b; Wang and Penner, 2009; Yu and Luo, 2009). The sensitivity of CCN particles to nucleation rates will depend on other atmospheric conditions, including primary emission rates and the amount of condensable vapor. However, most studies show less than $20 \%$ changes in CCN concentrations at $0.2 \%$ supersaturation (hereafter defined as $\mathrm{CCN}(0.2 \%)$ ) in the boundary layer, resulting from uncertainties in the boundary layer nucleation rate (e.g., binary vs. ternary nucleation schemes in Pierce and Adams (2009b) and with vs. without activation nucleation in the boundary layer with binary nucleation above the boundary layer in Merikanto et al., 2009). Yu and Luo (2009) present more than a factor of two larger impact of nucleation to boundary layer $\mathrm{CCN}(0.4 \%)$ (CCN concentrations at $0.4 \%$ supersaturation) because it includes the contribution from the nucleation above the boundary layer (compared to the boundary layer nucleation only in other studies). Their reported impact may be large because it labels sulfate particles nucleated in plumes as nucleation, whereas other studies count them as primary particles. Although these studies have examined the effect of nucleation on CCN concentrations, there has been less study of how to numerically simulate nucleation properly in a global aerosol model.

Various global models with online sectional aerosol microphysics have chosen different cutoffs for the smallest simulated aerosol size. Several models have used a lower cutoff of $1 \mathrm{~nm}$ (Yu and Luo, 2009; Snow-Kropla et al., 2011). The choice of $1 \mathrm{~nm}$ is logical because the critical cluster size is $\sim 1 \mathrm{~nm}$; thus the entire size distribution is explicitly simulated. Other models have used lower size cutoffs of $3 \mathrm{~nm}$ (Spracklen et al., 2005, 2008) and $10 \mathrm{~nm}$ (Adams and Seinfeld, 2002; Trivitayanurak et al., 2008; Lee et al., 2009; Pierce and Adams, 2009c, b). The rationale for these larger cutoffs was several-fold: (1) the smallest particles have the shortest lifetimes with respect to coagulation, and thus their explicit simulation adds a disproportionate computational burden to the model; (2) they are only present sporadically in the atmosphere; and (3) until recently atmospheric measurements of aerosol number were generally for particles above 3 or $10 \mathrm{~nm}$ depending on the instrument. To avoid the high computational burden required to simulate the nucleation mode particles explicitly, a nucleation mode parameterization is commonly used in global aerosol models. Kerminen et al. (2004a) proposed a parameterization to account for the growth of fresh nuclei to larger sizes (hereafter referred to as the Kerminen parameterization). The Kerminen parameterization takes into account condensational growth of fresh nuclei and their coagulational scavenging by preexisting particles. However, it does not account for coagulational growth of nucleated particles (i.e., self-coagulation among nucleated particles), which may be important under high-nucleation events. We should mention that the most updated nucleation mode dynamics parameterization includes the effect of the nuclei self-coagulation (Anttila et al., 2010) and the elimination of the slightly inaccurate coagulation sink (Lehtinen et al., 2007) that are missing in the current version of GISS-TOMAS. Nonetheless, the Kerminen parameterization avoids simulating explicit nucleation mode dynamics and reduces the computational demand in a global model. To our knowledge, on the global scale, how the application of this parameterization at various lowest size boundaries impacts the aerosol number budgets has not been tested against an explicit aerosol microphysics model.

In this paper, we investigate the impact of the lowest size boundary on aerosol budgets and evaluate the Kerminen parameterization with different lower size boundaries against explicit nucleation mode dynamics, using the TOMAS aerosol microphysics module in the Goddard Institute for Space Studies General Circulation Model (GISS GCM) II-prime. With a size cutoff smaller than $10 \mathrm{~nm}$, a time 
step in the aerosol microphysics module shorter than $1 \mathrm{~h}$ may be preferred due to the short coagulational lifetime of the nucleation mode particles (Kerminen et al., 2004b). Thus, we also investigate the impact of the choice of time step in the TOMAS algorithm on aerosol number budgets. Sections 2 and 3 provide the description of the model and the setup for the simulations used for this work. Section 4 presents how the model aerosol number budgets are affected by the lowest size limit and a time step applied to the aerosol microphysical processes, and Sect. 5 is the conclusions.

\section{GISS-TOMAS description}

The TwO-Moment Aerosol Sectional (TOMAS) aerosol microphysics model (Adams and Seinfeld, 2002) has been implemented into the climate model of GISS GCM II-prime, referred to as the "GISS-TOMAS" model (Lee and Adams, 2010). The GISS GCM II-prime has horizontal grid dimensions of $4^{\circ}$ latitude and $5^{\circ}$ longitude, with nine vertical sigma layers including the stratosphere to the $10 \mathrm{hPa}$ level (Hansen et al., 1983); the pressure levels of the boundaries for the nine layers are 984, 934, 854, 720, 550, 390, 255, 150, 70, and $10 \mathrm{hPa}$. Only 1-2 layers are in the stratosphere, so this model essentially treats only tropospheric aerosol. A detailed description of the GISS GCM is found in Hansen et al. (1983). The parameterizations of convective and stratiform clouds are updated by Del Genio and Yao (1993) and Del Genio et al. (1996), respectively. Chemical tracers are advected every hour by the model winds using a quadratic upstream scheme (Prather, 1986); heat and moisture are advected with a similar scheme. The time step for tracer processes in the GCM is $1 \mathrm{~h}$, but the TOMAS aerosol microphysical processes use an internal, adaptive time step.

The TOMAS aerosol microphysics model uses a sectional approach that represents the aerosol size distribution by predicting the amount of aerosol in several size sections or "bins". TOMAS tracks two moments of the aerosol size distribution in each size bin: total aerosol number and mass. Total mass is decomposed into several aerosol species, allowing prediction of the size-resolved aerosol composition. The original configuration of the model has 30 size sections (denoted TOMAS-30), with the lower boundary of the smallest size bin being $10^{-21} \mathrm{~kg}$ dry mass, and each successive boundary has twice the mass of the previous boundary. This provides a size distribution that ranges approximately from $10 \mathrm{~nm}$ to $10 \mu \mathrm{m}$ in dry diameter, depending on aerosol density (see Fig. 1). TOMAS uses a moving sectional approach to treat water uptake; changes in water mass do not move particles between sections. Adams and Seinfeld (2002) provide a detailed description of the TOMAS model. The model tracks nine quantities for each size bin: sulfate mass, sea salt mass, mass of externally mixed elemental carbon (EC), mass of internally mixed EC (mixed with all other species), mass of hydrophobic organic matter (OM), mass of hydrophilic

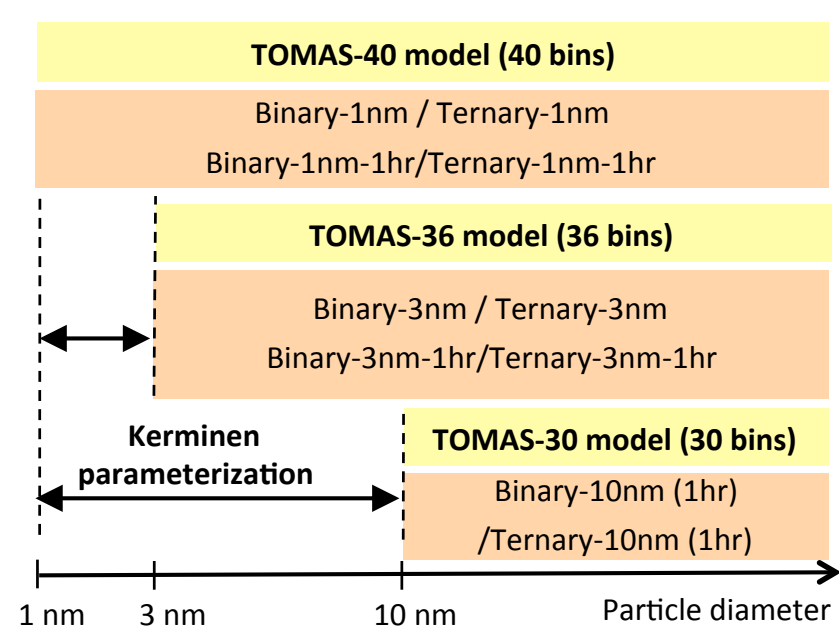

Fig. 1. Configurations of three TOMAS models used in this study and the number of simulations used for each model. Note that the TOMAS-36 and TOMAS-30 models use the nucleation mode dynamics parameterization (i.e., Kerminen parameterization) to account for the growth of nucleated particles to the model's lowest size boundary.

OM, mass of mineral dust, mass of ammonium, and mass of aerosol water and the number of aerosol particles in that size section. In addition, the model tracks one bulk aerosol-phase species, methanesulfonic acid (MSA), and six bulk gas-phase species: $\mathrm{H}_{2} \mathrm{O}_{2}, \mathrm{SO}_{2}$, dimethylsulfide (DMS), $\mathrm{H}_{2} \mathrm{SO}_{4}$, ammonia $\left(\mathrm{NH}_{3}\right)$, and a lumped gas-phase tracer representing oxidized organic vapors that can form secondary organic aerosol (SOA). Gas-phase $\mathrm{H}_{2} \mathrm{SO}_{4}$ is assumed to be in pseudo-steadystate equilibrium between chemical production and condensational/nucleation losses (Pierce and Adams, 2009a). Water uptake by sulfate, sea salt, and hydrophilic OM is accounted for in the model.

The TOMAS model used in this work includes previously developed modules for sulfate (Adams and Seinfeld, 2002), sea salt (Pierce and Adams, 2006), and carbonaceous aerosols (Pierce et al., 2007), and mineral dust (Lee et al., 2009). Emissions of primary particles are treated as in previous TOMAS studies and are briefly summarized here. The primary sulfate is emitted in two modes: fifteen percent of the mass is emitted to the first mode (number median diameter (NMD) of $10 \mathrm{~nm}$; geometric standard deviation (GSD) of 1.6), and the rest is emitted to the second mode (NMD of $70 \mathrm{~nm}$; GSD of 2) (Adams and Seinfeld, 2003). The size distribution of biofuel and biomass burning carbonaceous particles is assumed to have a NMD of $100 \mathrm{~nm}$ and a GSD of 2. Fossil fuel carbonaceous emission is assumed to have two modes based on Ban-Weiss et al. (2010). About $1.8 \%$ of the mass ( $64 \%$ of the total number) is emitted to a smaller mode (NMD of $17.5 \mathrm{~nm}$ and GSD of 1.6) and the rest is emitted to a larger mode (NMD of $60 \mathrm{~nm}$ and GSD of 1.9). Sea salt emission parameterization is based on Clarke et al. (2006), and 
mineral dust emission parameterization is based on Ginoux et al. (2001) and Marticorena and Bergametti (1995). The TOMAS model has been evaluated with ground-level measurement number and mass concentrations, deposition fluxes, and remote sensing observations (Adams and Seinfeld 2002; Pierce and Adams 2006; Pierce et al., 2007; Lee et al., 2009; Lee and Adams, 2010). In addition, the TOMAS coagulation and condensation algorithms have been evaluated against analytical solutions and have shown excellent agreement (Jung et al., 2006; Lee and Adams, 2012).

The descriptions of dry deposition and wet deposition are available in Adams and Seinfeld (2002) and Lee et al. (2009). Briefly, dry deposition uses the series resistance approach that treats size-dependent gravitational settling of particles and a size-dependent resistance in the quasi-laminar sublayer. Wet deposition occurs in large-scale (stratiform) and convective clouds and only in warm clouds. For in-cloud scavenging, the model uses modified Kohler theory to determine whether or not a particle is a CCN. The large-scale and convective clouds assume to have supersaturations of $0.2 \%$ and $1.0 \%$, respectively. The activation calculation is performed in each grid cell and time step with precipitation based on instantaneous aerosol size and composition. CCN concentrations presented in this paper are computed based on the monthly mean aerosol size and chemical composition fields (Pierce et al., 2007; Lee et al., 2009 for more details). The particles larger than the activation diameter at $0.2 \%$ supersaturation is counted as $\mathrm{CCN}(0.2 \%)$. When the activation diameter falls in between size boundaries, we perform interpolation to determine what fraction of particles in a size section activate.

\section{Representations of nucleation mode microphysics}

As shown in Fig. 1, the TOMAS-30 model uses the Kerminen parameterization to account for the growth of nucleated particles up to the first size bin, a diameter of $10 \mathrm{~nm}$, instead of explicitly simulating aerosol microphysics below $10 \mathrm{~nm}$ (Pierce and Adams, 2009b). The Kerminen parameterization predicts the formation rate of particles at the model's lower size boundary (i.e., $10 \mathrm{~nm}$ in the standard TOMAS-30 model) that occurs due to the nucleation rate, the condensational growth rate of the nucleated clusters by sulfuric acid and SOA precursor gases, and the coagulational losses of fresh nuclei with existing particles larger than the desired size (Kerminen et al., 2004a). The version of the parameterization used in this work does not consider the growth of the nuclei through self-coagulation and thus may lead to an underprediction of the $10 \mathrm{~nm}$ particle (or other desired size) formation rate in the presence of high new-particle formation rates (Kerminen et al., 2004a). Furthermore, Pierce and Adams (2009c) explain that the Kerminen parameterization assumes a constant growth rate from the critical cluster size to the model's lower size boundary based on the instantaneous growth rate when the particles were nucleated. If the true growth rate decreases during the time it takes a critical cluster to grow to the model's lower size boundary of $10 \mathrm{~nm}$, then the Kerminen parameterization would overpredict the $J_{10}$ rate.

To find out how the model-predicted global aerosol concentrations depend on the lower size cutoff (size at which the Kerminen parameterization predicts the formation rate of particles), three model configurations are used in this paper (shown in Fig. 1). TOMAS-30 is our original model configuration that has $10 \mathrm{~nm}$ as its lowest size boundary. The Kerminen parameterization is used to predict the formation rate of $10 \mathrm{~nm}$ particles from growth of nuclei. The TOMAS-36 model extends the lowest size boundary down to $3 \mathrm{~nm}$, and the Kerminen parameterization is applied to predict the formation rate of $3 \mathrm{~nm}$ particles. The TOMAS-40 model has the lowest size boundary extended to $1 \mathrm{~nm}$. Explicit aerosol microphysics (i.e., the TOMAS model itself) is used to simulate the nucleation mode dynamics in this case except that the Kerminen parameterization is still applied to get the formation rate of $1 \mathrm{~nm}$ particles when the diameter of critical nuclei particles is smaller than $1 \mathrm{~nm}$.

When the explicit microphysics is used for the nucleation mode particles (i.e., TOMAS-36 and TOMAS-40 models), it may be necessary to use a shorter time step in the aerosol microphysics module than $1 \mathrm{~h}$ as used in the TOMAS-30 model due to the fast microphysics of the nucleation mode particles (Kerminen et al., 2004b). To find out how the choice of a time step for aerosol microphysical processes affects aerosol number budgets, a $10 \mathrm{~min}$ time step is used for TOMAS-36 and TOMAS-40 models in one set of simulations, and the $1 \mathrm{~h}$ time step (i.e., the original TOMAS-30 default) is used for another set of simulations (denoted with " $1 \mathrm{hr}$ " added to the names of the simulations in Fig. 1).

The TOMAS algorithm has two subroutines, condensation/nucleation and coagulation, each of which uses an adaptive internal time step. The $10 \mathrm{~min}$ or $1 \mathrm{~h}$ time step described here represents the "master" time step for microphysics that governs how frequently TOMAS alternates between condensation/nucleation and coagulation. In the case of the $1 \mathrm{~h}$ time step, condensation/nucleation occurs first for $1 \mathrm{~h}$ and then coagulation occurs for the full hour. For the $10 \mathrm{~min}$ time step, six loops happen in the TOMAS microphysics algorithm (i.e., condensation/nucleation occurs first for $10 \mathrm{~min}$, then coagulation occurs for $10 \mathrm{~min}$, back to condensation/nucleation for the next $10 \mathrm{~min}$ and so forth until the total time becomes $1 \mathrm{~h}$ ). Even when the "master" time step is $1 \mathrm{~h}$, however, both condensation/nucleation and coagulation may subdivide this into smaller, internal time steps according to their adaptive schemes.

The TOMAS-40 models with 10 min time steps are considered to be the reference cases against which the other models are compared. Because of the uncertainties in the nucleation theories themselves and other challenges associated with global microphysical simulations, this does not imply that the reference cases are perfect simulations of the real 


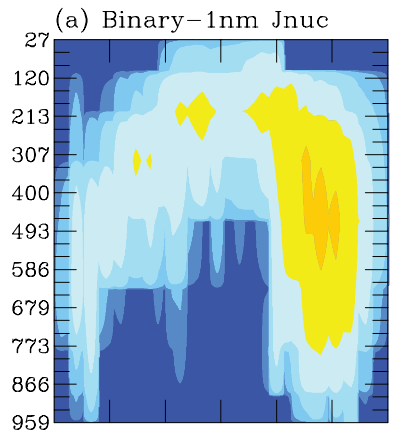

(d) Ternary-1nm Jnuc

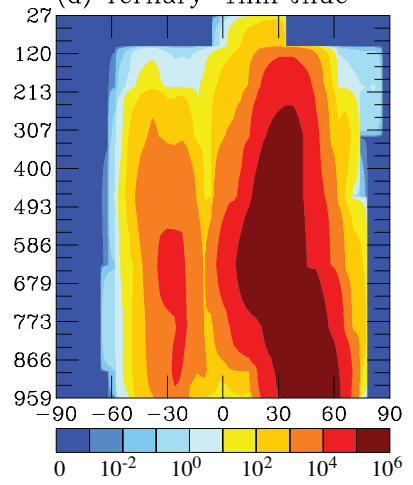

(b) Binary-1nm CN10

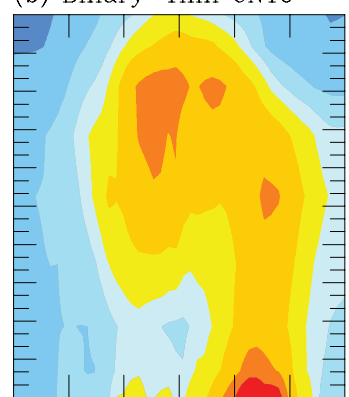

(e) Ternary-1nm CN10

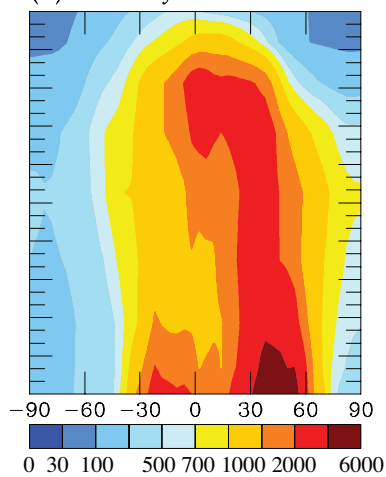

(c) Binary $-1 \mathrm{~nm} \operatorname{CCN}(0.2 \%)$

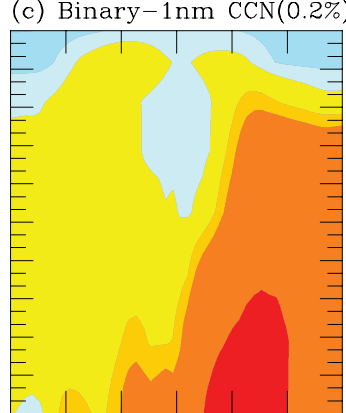

(f) Ternary-1nm $\operatorname{CCN}(0.2 \%)$

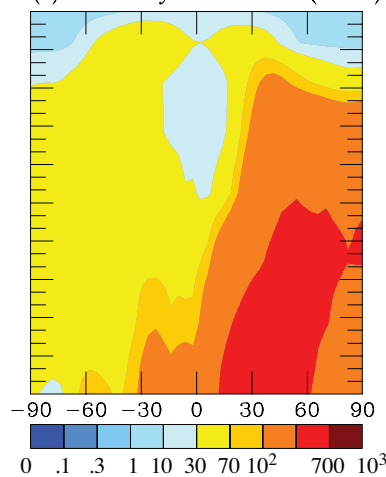

Fig. 2. Pressure (hPa) vs. latitude maps for March-to-May averaged nucleation rates $\left(J_{\text {nuc }}\right)\left(\mathrm{cm}^{-3} \mathrm{~s}^{-1}\right.$ at $273 \mathrm{~K}$ and 1 atm), CN10 $\left(D_{\mathrm{p}} \geq\right.$ $10 \mathrm{~nm})\left(\mathrm{cm}^{-3}\right.$ at $273 \mathrm{~K}$ and $\left.1 \mathrm{~atm}\right), \mathrm{CCN}(0.2 \%)\left(\mathrm{cm}^{-3}\right.$ at $273 \mathrm{~K}$ and $\left.1 \mathrm{~atm}\right)$ for Binary-1 $\mathrm{nm}$ and Ternary-1 nm simulations.

atmosphere. Rather, here we use the reference case to denote a simulation with a numerically accurate simulation of nucleation mode dynamics and free of errors resulting from assumptions made in the Kerminen parameterization.

To investigate the impact of uncertainties in nucleation rates on the representation of nucleation mode dynamics, each model configuration is used for two nucleation scenarios: a low-nucleation-rate scenario with Vehkamaki et al. (2002) binary nucleation (nucleation is generally confined to the free troposphere) and a high-nucleation-rate scenario with Napari et al. (2002) ternary nucleation. Uncertainties in nucleation rates are represented using binary and ternary nucleation because the binary nucleation parameterization underpredicts nucleation rates in the boundary layer whereas the ternary nucleation parameterization produces unrealistically high rates (Jung et al., 2006). We would like to note that the TOMAS model used in this study does not include any additional boundary nucleation scheme such as the clusteractivation nucleation scheme because it has been shown that the ternary nucleation scheme used here does predict frequent nucleation events in the boundary layer (Jung et al., 2006, 2008, 2010).

Figure 1 shows the ten simulations that will be discussed in this paper. The simulation names reflect the important features in each simulation: nucleation parameterization, size cutoff, and aerosol microphysical time step. As noted already, the Binary- $1 \mathrm{~nm}$ and Ternary- $1 \mathrm{~nm}$ are the numerical benchmark simulations against which all biases in the aerosol number budgets are calculated. Regarding the computational burden of each model configuration, based on a one-month simulation with binary nucleation using a $600 \mathrm{Mhz}$ single processor of an SGI Origin 300, it takes about $58 \mathrm{~h}$ for TOMAS-30. For TOMAS-36, it takes $\sim 73 \mathrm{~h}$ using the $1 \mathrm{~h}$ time step and $\sim 122 \mathrm{~h}$ using the $10 \mathrm{~min}$ time step. Finally, for TOMAS-40, it takes $\sim 79 \mathrm{~h}$ using the $1 \mathrm{~h}$ time step and $\sim 123 \mathrm{~h}$ using the $10 \mathrm{~min}$ time step.

\section{Results and discussion}

All model results presented in this paper are based on a threemonth average from March to May using the GCM climatological meteorology after a three-month spin-up. Our results are limited to three-month averages due to the computational demand in the TOMAS-36 and TOMAS-40 models, but this time period should be sufficient for determining the relative errors due to differences in model-configuration assumptions. Figure 2 shows pressure-latitude maps of the three-month average nucleation rates $\left(J_{\text {nuc }}\right), \mathrm{CN} 10$ (particles with diameters larger than $10 \mathrm{~nm}$ ) concentrations, and $\mathrm{CCN}(0.2 \%)$ for the Binary- $1 \mathrm{~nm}$ and Ternary- $1 \mathrm{~nm}$ simulations. Figure 2 shows a very similar pattern to Fig. 3 in Pierce and Adams (2009c) that also presents annually averaged values of the same quantities. In Fig. $2 \mathrm{a}$ and d, the $J_{\text {nuc }}$ 
Table 1. Global three-month average of the nucleation rate $\left(J_{\text {nuc }}\right)$, the formation rate of particles larger than $10 \mathrm{~nm}$ from nucleated particles $\left(J_{10}\right)$, the ultrafine-mode $\left(10 \mathrm{~nm} \leq D_{\mathrm{p}} \leq 70 \mathrm{~nm}\right)$ burden and lifetime, and the CCN mode $\left(D_{\mathrm{p}}>70 \mathrm{~nm}\right)$ burden and lifetime in the six basic scenarios. Values normalized by tropospheric volume at $273 \mathrm{~K}$ and $1 \mathrm{~atm}$, assuming $12000 \mathrm{~m}$ as the height of the tropopause.

\begin{tabular}{|c|c|c|c|c|c|c|}
\hline Simulations & $\begin{array}{r}J_{\text {nuc }} \\
{\left[\mathrm{cm}^{-3} \mathrm{day}^{-1}\right]}\end{array}$ & $\begin{array}{r}J_{10} \\
{\left[\mathrm{~cm}^{-3} \mathrm{day}^{-1}\right]}\end{array}$ & $\begin{array}{l}\text { Ultrafine mode } \\
\text { burden }\left[\mathrm{cm}^{-3}\right]\end{array}$ & $\begin{array}{l}\text { Ultrafine mode } \\
\text { lifetime [days] }\end{array}$ & $\begin{array}{r}\mathrm{CCN} \text { mode } \\
\text { burden }\left[\mathrm{cm}^{-3}\right]\end{array}$ & $\begin{array}{r}\text { CCN mode } \\
\text { lifetime [days] }\end{array}$ \\
\hline Ternary-1 nm & $3.4 \times 10^{8}$ & 116 & 758 & 5.9 & 142 & 5.5 \\
\hline Ternary-3 nm & $4.6 \times 10^{8}$ & 126 & 942 & 7.0 & 154 & 5.7 \\
\hline Ternary-10 nm & $4.5 \times 10^{8}$ & 3367 & 1380 & 0.4 & 168 & 5.7 \\
\hline Binary-1 nm & $4.2 \times 10^{4}$ & 47 & 458 & 6.7 & 115 & 5.1 \\
\hline Binary-3 nm & $1.2 \times 10^{4}$ & 58 & 538 & 6.8 & 120 & 5.3 \\
\hline Binary-10 nm & $1.6 \times 10^{3}$ & 365 & 885 & 2.4 & 128 & 5.5 \\
\hline
\end{tabular}

in Ternary- $1 \mathrm{~nm}$ is several orders of magnitude higher than that in Binary- $1 \mathrm{~nm}$ and is ubiquitous throughout the troposphere in the regions that receive sunlight between March and May. The nucleation in Binary-1 nm occurs in high altitudes and high latitude but does not predict much nucleation in the boundary layer. The distribution of $\mathrm{CN} 10$ concentrations, shown in Fig. $2 b$ and e, is similar to the nucleation rate except for the surface layer where primary particles contribute significantly to CN10 concentrations. However, the difference in $\mathrm{CN} 10$ concentrations between the two nucleation mechanisms is much smaller than the difference in $J_{\text {nuc }}$ because a higher nucleation rate results in slower condensational growth rates (due to larger condensation sinks) and faster coagulation removal rates, which dampen the $\mathrm{CN} 10$ to changes in nucleation. Figure $2 \mathrm{c}$ and $\mathrm{f}$ show fairly insensitive $\mathrm{CCN}(0.2 \%)$ to the nucleation rate because the probability of growth of nucleated particles to $\mathrm{CCN}$-sized particles decreases with higher nucleation rate (Pierce and Adams, 2009b). The similar results in Pierce and Adams (2009c) were annually averaged showing that these results are not largely sensitive to the choice of three-month seasons in the current work, and our key conclusions are unlikely to be changed by examining an annual average.

\subsection{Globally averaged aerosol number budgets}

Simulating aerosol microphysics in the nucleation mode with the Kerminen parameterization is influenced by the choice of the lowest size boundary. Table 1 presents the global-average aerosol budgets for the six simulation scenarios including the $J_{\text {nuc }}$ (nucleation rate), the formation rate of particles larger than $10 \mathrm{~nm}$ from nucleated particles $\left(J_{10}\right)$, the number concentration and lifetime of ultrafinemode particles $\left(10 \mathrm{~nm} \leq D_{\mathrm{p}} \leq 70 \mathrm{~nm}\right)$ and $\mathrm{CCN}$ mode particles $\left(70 \mathrm{~nm}<D_{\mathrm{p}}\right)$ : Binary- $1 \mathrm{~nm}$, Ternary- $1 \mathrm{~nm}$, Binary$3 \mathrm{~nm}$, Ternary- $3 \mathrm{~nm}$, Binary-10 nm and Ternary- $10 \mathrm{~nm}$. Compared to the $1 \mathrm{~nm}$ reference cases (i.e., Ternary- $1 \mathrm{~nm}$, Binary$1 \mathrm{~nm}$ ), globally averaged $J_{\text {nuc }}$ is overpredicted using the $3 \mathrm{~nm}$ and $10 \mathrm{~nm}$ boundaries for ternary nucleation by $\sim 35 \%$ but is underpredicted for binary nucleation by $70-96 \%$. The Kerminen parameterization tends to overpredict globally
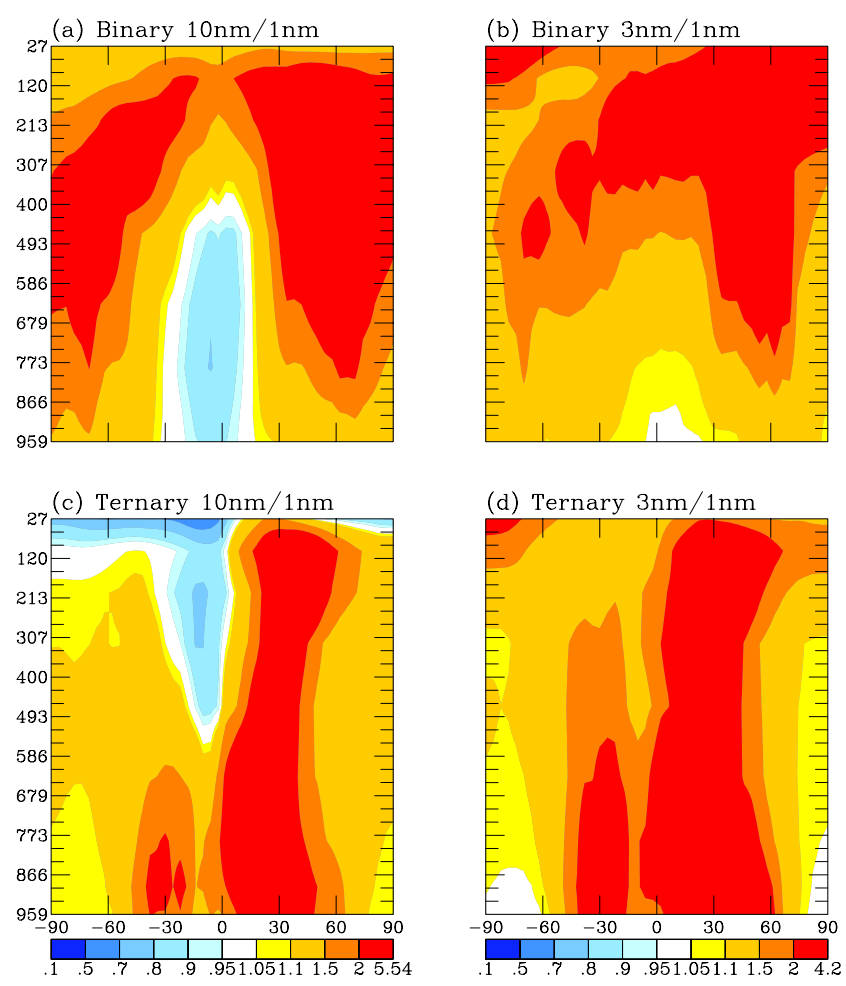

Fig. 3. Pressure (hPa) vs. latitude maps for March-to-May averaged ratios of $\mathrm{CN} 10$ concentrations from the following scenarios: (a) Binary-10 nm to Binary-1 nm, (b) Binary- $3 \mathrm{~nm}$ to Binary-1 nm, (c) Ternary- $10 \mathrm{~nm}$ to Ternary- $1 \mathrm{~nm}$, and (d) Ternary- $3 \mathrm{~nm}$ to Ternary$1 \mathrm{~nm}$.

averaged $J_{10}$ in the $3 \mathrm{~nm}$ and the $10 \mathrm{~nm}$ simulations. The overprediction of $J_{10}$ in the $3 \mathrm{~nm}$ simulations is only by $24 \%$ for binary and $8 \%$ for ternary, whereas the $10 \mathrm{~nm}$ simulations overpredict significantly by a factor of 7 for binary and a factor of 28 for ternary. Interestingly, with the Kerminen parameterization, the binary nucleation simulations overpredict $J_{10}$ despite underpredicting $J_{\text {nuc }}$. Compared to the reference simulations, the aerosol burden and lifetime of the ultrafine mode in the $3 \mathrm{~nm}$ simulations differ by a few percent 
Table 2. Same as Table 1 but for the four sensitivity scenarios.

\begin{tabular}{|c|c|c|c|c|c|c|}
\hline Simulations & {$\left[\mathrm{cm}^{-3} \mathrm{day}^{-1}\right]$} & {$\left[\mathrm{cm}^{-3} \mathrm{day}^{J_{10}}\right]$} & $\begin{array}{l}\text { Ultrafine mode } \\
\text { burden }\left[\mathrm{cm}^{-3}\right]\end{array}$ & $\begin{array}{l}\text { Ultrafine mode } \\
\text { lifetime [days] }\end{array}$ & $\begin{array}{r}\mathrm{CCN} \text { mode } \\
\text { burden }\left[\mathrm{cm}^{-3}\right]\end{array}$ & $\begin{array}{r}\mathrm{CCN} \text { mode } \\
\text { lifetime [days] }\end{array}$ \\
\hline Ternary-1 nm & $3.4 \times 10^{8}$ & 116 & 758 & 5.9 & 142 & 5.5 \\
\hline Ternary-3 nm & $4.6 \times 10^{8}$ & 126 & 942 & 7.0 & 154 & 5.7 \\
\hline Binary-1 nm & $4.2 \times 10^{4}$ & 47 & 458 & 6.7 & 115 & 5.1 \\
\hline Binary-3 nm & $1.2 \times 10^{4}$ & 58 & 538 & 6.8 & 120 & 5.3 \\
\hline Ternary-1 nm-1 h & $3.3 \times 10^{8}$ & 132 & 753 & 5.3 & 148 & 5.4 \\
\hline Ternary-3 nm-1 h & $4.4 \times 10^{8}$ & 135 & 942 & 6.5 & 160 & 5.7 \\
\hline Binary- $1 \mathrm{~nm}-1 \mathrm{~h}$ & $3.9 \times 10^{4}$ & 50 & 460 & 6.4 & 121 & 5.2 \\
\hline Binary- $3 \mathrm{~nm}-1 \mathrm{~h}$ & $1.2 \times 10^{4}$ & 62 & 539 & 6.5 & 125 & 5.3 \\
\hline
\end{tabular}

to $\sim 25 \%$, and the $10 \mathrm{~nm}$ simulations show much larger errors than do the $3 \mathrm{~nm}$ simulations. Even though $J_{10}$ is overpredicted significantly in the $10 \mathrm{~nm}$ simulations, the aerosol burden in the ultrafine mode is overpredicted only by about $80-90 \%$, which can be explained by the shorter lifetime of the ultrafine mode due to increased coagulation and reduced growth (keeping the particles at smaller sizes where coagulational losses are faster). In all cases, $\mathrm{CCN}$ budgets are less affected by the choice of lower size boundary than ultrafinemode budgets (and thus CN10 budgets).

We note that the underestimated $J_{\text {nuc }}$ in $10 \mathrm{~nm}$ simulations (compared to the $1 \mathrm{~nm}$ simulations) for binary nucleation can be explained with the higher condensational sink (i.e., higher $\left.J_{10}\right)$. However, this is not the case for the ternary nucleation. During fast nucleation events by ternary nucleation, the small nucleation mode particles $(1-3 \mathrm{~nm})$ can be a relatively important condensational sink as their number concentration is very high when nucleation occurs, resulting in lower nucleation rates. However, when nucleation is not occurring, the number concentration of the nucleation mode and the contribution of these particles to the condensational sink is generally very small. This hypothesis can be also supported by the lower sulphuric acid concentration in TOMAS-40 over areas showing very fast nucleation rate. This explains why the $J_{10}$ overprediction is so much worse in the $10 \mathrm{~nm}$ simulation (compared to the $1 \mathrm{~nm}$ simulation) with the ternary nucleation.

In the GISS-TOMAS model, the Kerminen parameterization overpredicts $J_{10}$ (or $J_{3}$, defined as a particle formation rate for a particle larger than $3 \mathrm{~nm}$ ) systematically, which leads to an overprediction of CN10 concentrations. Some of the known drawbacks in the Kerminen parameterization (e.g., no coagulational growth) do not explain the overprediction seen in the GISS-TOMAS model. Also, our results do not agree with Kerminen et al. (2004a), which does not show a consistent overprediction in $J_{3}, J_{10}$, and total number concentrations by the parameterization compared to their box-scale explicit dynamics model at same nucleation rates. The error in $J_{3}$ and $J_{10}$ by the Kerminen parameterization might be improved with the revised formulation (Lehtinen et al., 2007; Anttila et al., 2010), but this is unlikely to explain the overpredicted $J_{10}$ seen in this work. Nevertheless, we found that the Kerminen parameterization with the $3 \mathrm{~nm}$ boundary introduces much less error in aerosol number predictions than that with the $10 \mathrm{~nm}$ boundary, which is consistent with Kerminen et al. (2004a).

Perhaps the most likely explanation for the overprediction of $J_{10}$ seen here is that the Kerminen parameterization calculates the survival probability from $1 \mathrm{~nm}$ to 3 or $10 \mathrm{~nm}$ based on the current conditions of the grid cell, and then the growth is assumed to occur instantaneously. This is the instantaneous growth rate assumption mentioned in Sect. 3. However, in reality, growth rates are frequently $\sim 2 \mathrm{~nm} \mathrm{~h}^{-1}$ or less so that growth to $10 \mathrm{~nm}$ will take several hours during which conditions will change. Since photochemical activity, condensable vapor concentrations, and growth rates are all quite high during the peak of a nucleation event, basing a calculated survival on instantaneous conditions during an event would likely lead to an overprediction in $J_{10}$. Moreover, the overprediction would be expected to be much more severe with a $10 \mathrm{~nm}$ cutoff compared to a $3 \mathrm{~nm}$ cutoff, consistent with the results shown here. For a very pristine atmosphere with a nucleation event (i.e., convective cloud outflow areas), the overprediction in $J_{10}$ may be worse by missing losses by selfcoagulation within the nucleation mode by the Kerminen parameterization.

Unlike the lower size limit, global-average CN10 budgets are quite insensitive to the time step change in aerosol microphysical processes. Table 2 presents globally averaged aerosol number budgets for the remaining four simulations: Binary- $1 \mathrm{~nm}-1 \mathrm{~h}$, Ternary- $1 \mathrm{~nm}-1 \mathrm{~h}$, Binary- $3 \mathrm{~nm}-1 \mathrm{~h}$ and Ternary- $3 \mathrm{~nm}-1 \mathrm{~h}$. Compared to the simulations with a shorter time step presented in Table 1, aerosol budgets in these simulations show a small difference (mostly a few percent). Although small, we found some systematic differences when changing the aerosol microphysical time step. For example, with the $1 \mathrm{~h}$ time step, global-average $J_{\text {nuc }}$ is $2-6 \%$ lower while global-average $J_{10}$ is $6-13 \%$ higher. Globalaverage $\mathrm{CCN}$ mode burdens are higher by $4-5 \%$, which might be explained with $12-20 \%$ higher condensational 

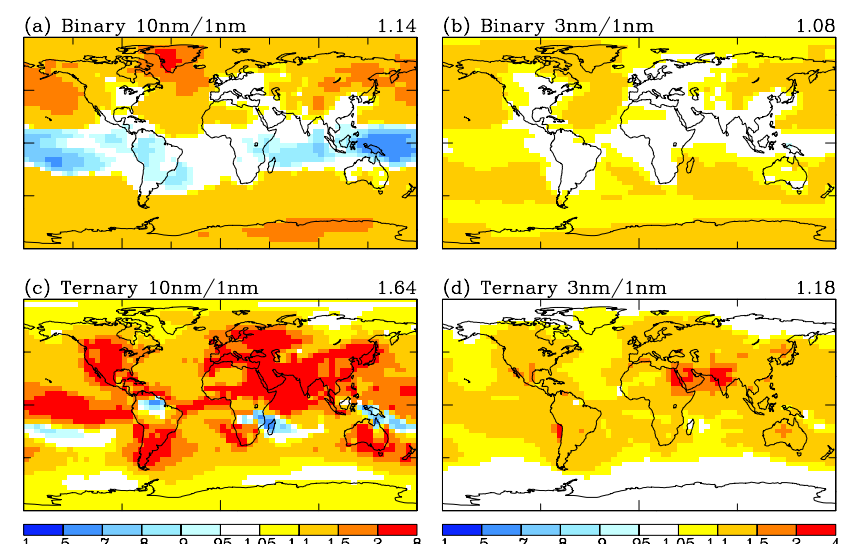

Fig. 4. Latitude vs. longitude maps of March-to-May average ratios of CN10 concentrations in the first vertical layer from the following scenarios: (a) Binary-10 nm to Binary-1 nm, (b) Binary-3 nm to Binary-1nm, (c) Ternary-10 nm to Ternary-1 nm, and (d) Ternary$3 \mathrm{~nm}$ to Ternary- $1 \mathrm{~nm}$. The value on the top right of each figure is a global average of the ratios displayed in the map.

growth rates for particles with diameters larger than $70 \mathrm{~nm}$ (not shown). Global-average CN10 burdens appear to be insensitive to the time step change. In conclusions, these results indicate that using a $1 \mathrm{~h}$ time step can lead to quite satisfactory results for these simulations but that a $10 \mathrm{~nm}$ lower size boundary can result in significant biases.

\subsection{Impact on spatial distributions of $\mathrm{CN10}$ and $\operatorname{CCN}(0.2 \%)$}

Figure 3 shows pressure-latitude maps for March-to-May averaged ratios of $\mathrm{CN} 10$ concentrations in the 3 or $10 \mathrm{~nm}$ simulations compared to those in the $1 \mathrm{~nm}$ benchmark simulations. Unlike global-average quantities, they show much larger differences in CN10 in some regions with the maximum being more than a factor of four. The overpredictions of CN10 in the $3 \mathrm{~nm}$ and $10 \mathrm{~nm}$ simulations occur throughout the troposphere for both binary and ternary nucleation, and the large differences occur at high-nucleation-rate regions as shown in Fig. 2. The higher CN10 concentrations in the 3 and $10 \mathrm{~nm}$ simulations are likely a result of the overpredicted $J_{10}$ or $J_{3}$ by the Kerminen parameterization, although other factors may play a role. Unlike the $3 \mathrm{~nm}$ simulations, the $10 \mathrm{~nm}$ simulations (shown in Fig. 3a and c) show underpredicted CN10 in some parts of the tropics for both binary and ternary nucleation schemes. The underpredicted CN10 areas show no nucleation events for the binary nucleation and, for the ternary nucleation, there are noticeably lower nucleation rates and lower free-ammonia concentrations in TOMAS-30 than TOMAS-40. This clearly shows that the choice of the lowest size boundary is important for CN10 prediction. Similar to the global-average $\mathrm{CN} 10$ predictions, the zonal average of ratios of $\mathrm{CN} 10$ concentrations in the $3 \mathrm{~nm}$ simulations
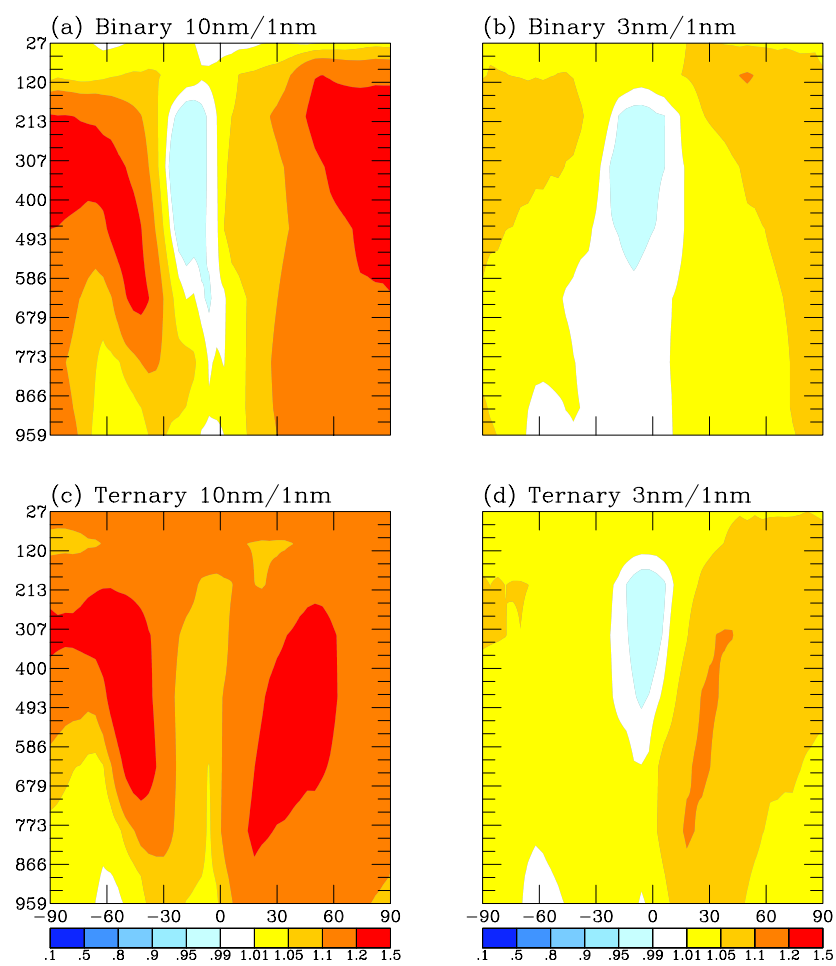

Fig. 5. Pressure (hPa) vs. latitude maps for March-to-May averaged ratios of $\mathrm{CCN}(0.2 \%)$ concentrations from the following scenarios: (a) Binary-10 nm to Binary- $1 \mathrm{~nm}$, (b) Binary-3 nm to Binary$1 \mathrm{~nm}$, (c) Ternary-10 $\mathrm{nm}$ to Ternary- $1 \mathrm{~nm}$, and (d) Ternary-3 $\mathrm{nm}$ to Ternary-1 nm.

to those in the $1 \mathrm{~nm}$ simulations with $1 \mathrm{~h}$ time steps are almost identical to the 10 min time step shown in Fig. $3 \mathrm{~b}$ and $\mathrm{d}$. The change in the $\mathrm{CN} 10$ predictions when the time step is changed from the $10 \mathrm{~min}$ to $1 \mathrm{~h}$ is only a few percent (not shown).

Figure 4 shows latitude-longitude maps of ratios of the lowermost-layer CN10 concentrations in the $10 \mathrm{~nm}$ or $3 \mathrm{~nm}$ simulations compared to those in the $1 \mathrm{~nm}$ benchmark simulations. The spatial patterns of the $\mathrm{CN} 10$ prediction errors are different between the two nucleation mechanisms. Comparing lower size cutoffs, the patterns are similar but the $10 \mathrm{~nm}$ cutoff consistently shows larger errors. Averaged across the entire lowermost layer, the $3 \mathrm{~nm}$ simulations introduces $\sim 10$ to $\sim 20 \%$ difference for the binary and ternary, respectively; in the $10 \mathrm{~nm}$ simulations, the differences are $\sim 15$ to $\sim 60 \%$. The surface-layer CN10 in the $3 \mathrm{~nm}$ simulations agrees with the $1 \mathrm{~nm}$ benchmark simulation within $30 \%$ in most regions, but the error can be a factor of 2 in the Middle East, where there is a high nucleation rate in Ternary- $3 \mathrm{~nm}$, reflecting the overprediction of $J_{10}$ in the $3 \mathrm{~nm}$ simulation. Again, for the $3 \mathrm{~nm}$ and $1 \mathrm{~nm}$ simulations with the $1 \mathrm{~h}$ time step, the surfacelayer CN10 agrees very well (within a few percent in most regions) to those with $10 \mathrm{~min}$ time step (not shown). The small impact on $\mathrm{CN} 10$ by the choice of time step may be a 

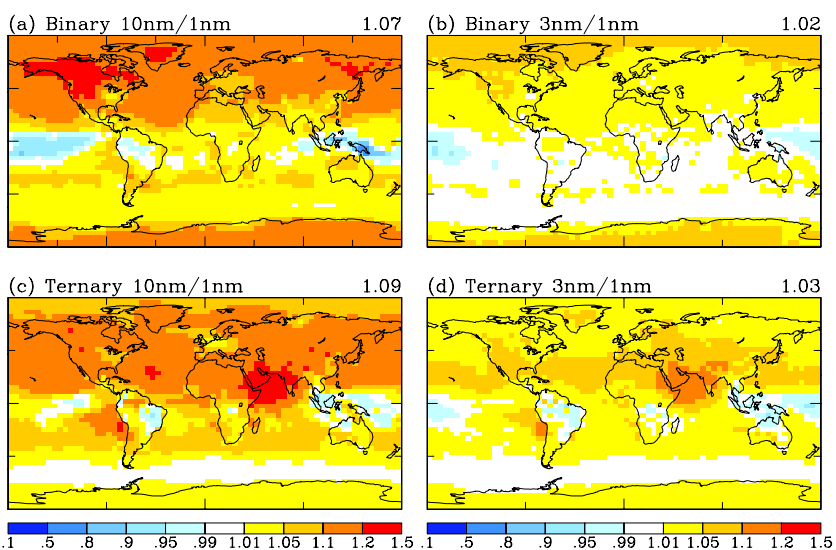

Fig. 6. Latitude vs. longitude maps of March-to-May average ratios of $\mathrm{CCN}(0.2 \%)$ concentrations in the first vertical layer from the following scenarios: (a) Binary-10 nm to Binary-1 nm, (b) Binary$3 \mathrm{~nm}$ to Binary- $1 \mathrm{~nm}$, (c) Ternary- $10 \mathrm{~nm}$ to Ternary- $1 \mathrm{~nm}$, and (d) Ternary- $3 \mathrm{~nm}$ to Ternary- $1 \mathrm{~nm}$. The value on the top right of each figure is a global average of the ratios displayed in the map.

result of higher condensational growth rate and shorter lifetime (Sect. 4.1).

Figure 5 shows zonal-average ratios of $\mathrm{CCN}(0.2 \%)$ in the $3 \mathrm{~nm}$ and $10 \mathrm{~nm}$ simulations with those in the $1 \mathrm{~nm}$ benchmark simulations. Unlike Fig. 3, the spatial distribution of $\mathrm{CCN}(0.2 \%)$ ratios is similar between binary and ternary nucleation, but the $3 \mathrm{~nm}$ and $10 \mathrm{~nm}$ simulations are somewhat different from each other. Overall error in the $\operatorname{CCN}(0.2 \%)$ prediction by using a $3 \mathrm{~nm}$ cutoff is no more than about $10 \%$ in any location. For the $10 \mathrm{~nm}$ cutoff, the error is generally less than $20 \%$, but is as high as $50 \%$ in some locations.

The spatial distribution of the lowermost-layer $\mathrm{CCN}(0.2 \%)$ ratios (shown in Fig. 6) is similar to, but smaller than, the lowermost-layer CN10 (shown in Fig. 4). The $\mathrm{CCN}(0.2 \%)$ in the $3 \mathrm{~nm}$ simulations differ from the $1 \mathrm{~nm}$ benchmark by less than $5 \%$ in most regions, while that in the $10 \mathrm{~nm}$ simulations is overpredicted by $10-50 \%$ in most of the Northern Hemisphere for both nucleation mechanisms. Overall, $\mathrm{CCN}(0.2 \%)$ is affected by the choice of lower size limit but to a much lesser degree than $\mathrm{CN} 10$, and the $\mathrm{CCN}(0.2 \%)$ difference is quite similar between two nucleation schemes, which reflects the insensitivity of $\mathrm{CCN}(0.2 \%)$ to nucleation.

The choice of microphysical time step has a negligible impact on $\mathrm{CN} 10$ but a greater influence on $\mathrm{CCN}(0.2 \%)$, at least in some locations. Figure 7 presents spatial distributions of $\mathrm{CCN}(0.2 \%)$ ratios of Ternary- $3 \mathrm{~nm}-1 \mathrm{~h}$ to Ternary$3 \mathrm{~nm}$ and Ternary- $1 \mathrm{~nm}-1 \mathrm{~h}$ to Ternary- $1 \mathrm{~nm}$ simulations. The binary nucleation cases are not shown because they have similar spatial trends and magnitudes. The biases in the $\mathrm{CCN}(0.2 \%)$ using the $1 \mathrm{~h}$ time step in both zonal averages, shown in Fig. 7, are quite similar between the $3 \mathrm{~nm}$ and the $1 \mathrm{~nm}$ cutoffs and are mostly within $5-10 \%$; the same is true
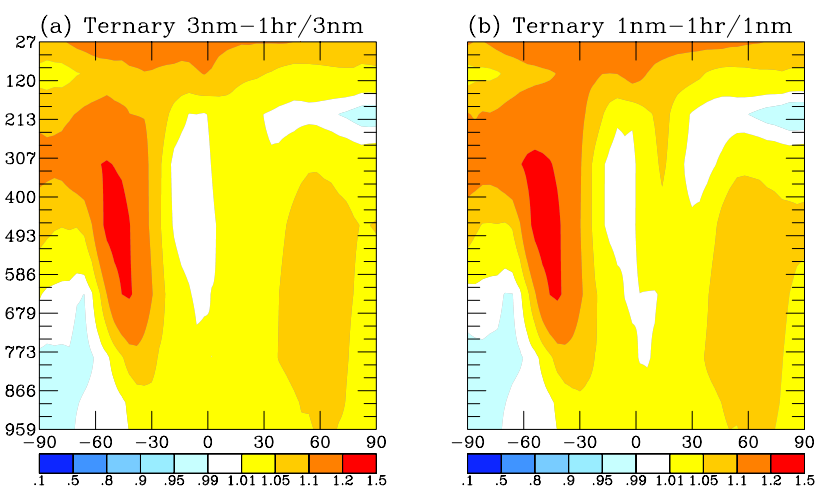

Fig. 7. Same as Fig. 5 but for the following scenarios: (a) Ternary$3 \mathrm{~nm}-1 \mathrm{~h}$ to Ternary- $3 \mathrm{~nm}$ and (b) Ternary- $1 \mathrm{~nm}-1 \mathrm{~h}$ to Ternary- $1 \mathrm{~nm}$.

at the model surface (not shown). In fact, when comparing with the $1 \mathrm{~nm}$ simulation with $1 \mathrm{~h}$ time step, the biases in the $\operatorname{CCN}(0.2 \%)$ from the $10 \mathrm{~nm}$ simulations turn out to be smaller (see Figs. 8 and 9) than the comparisons with the benchmark simulations (see Figs. 5 and 6) but still larger than the $3 \mathrm{~nm}$ simulations with the $1 \mathrm{~h}$ time step. Also, Fig. 8 shows a very similar spatial pattern of the $\mathrm{CCN}(0.2 \%)$ errors between the $10 \mathrm{~nm}$ and $3 \mathrm{~nm}$ simulations. Averaged across the entire lowermost layer, using the same time step, the $10 \mathrm{~nm}$ simulations introduces a $\sim 3$ to $\sim 6 \%$ difference for the binary and ternary, respectively (see Fig. 9); using different time steps, the errors by the $10 \mathrm{~nm}$ simulations are $7 \%$ and $9 \%$ (see Fig. 6). This indicates that the larger $\mathrm{CCN}(0.2 \%)$ deviation by the $10 \mathrm{~nm}$ simulations (shown in Fig. 5a and c) is partly attributed to the different time step. Thus, the choice of a time step is as important in predicting $\mathrm{CCN}(0.2 \%)$ as the choice of the lower size limit.

\section{Conclusions}

We investigated the representation of the nucleation mode $\left(1 \mathrm{~nm}<D_{\mathrm{p}}<10 \mathrm{~nm}\right)$ particle dynamics in a global model with aerosol microphysics by comparing explicit representations of nucleation mode aerosol to parameterizations of nucleation mode microphysics. This study uses the global aerosol microphysics model GISS-TOMAS, varying its lowest aerosol diameter boundary: $1 \mathrm{~nm}, 3 \mathrm{~nm}$, and $10 \mathrm{~nm}$. The microphysics of nucleation mode particles are explicitly resolved with the $1 \mathrm{~nm}$ boundary. The model with the $10 \mathrm{~nm}$ and $3 \mathrm{~nm}$ boundaries uses a nucleation mode dynamics parameterization proposed by Kerminen et al. (2004a), to account for the growth of nucleated particles to $10 \mathrm{~nm}$ and $3 \mathrm{~nm}$, respectively. We also compared a $10 \mathrm{~min}$ time step versus a $1 \mathrm{~h}$ time step in the TOMAS algorithm to investigate the impact of time step on aerosol number predictions. The simulations with $1 \mathrm{~nm}$ size cutoff and 10 min time step are 

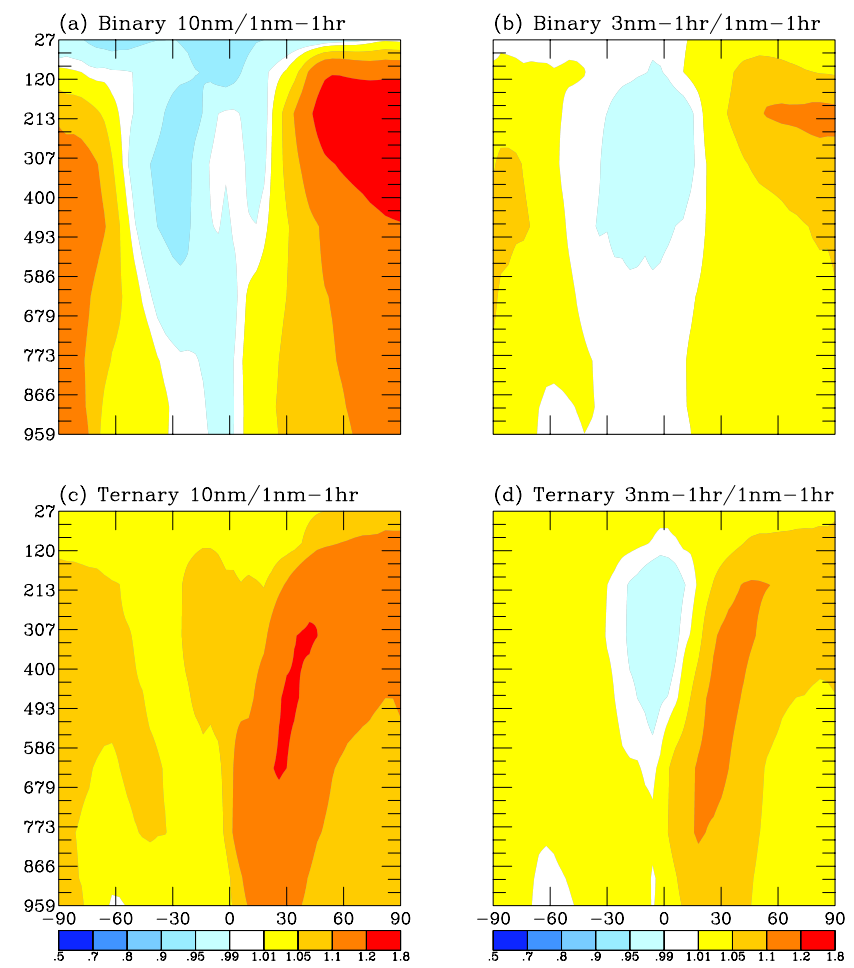

Fig. 8. Same as Fig. 5 but for the following scenarios: (a) Binary$10 \mathrm{~nm}$ to Binary- $1 \mathrm{~nm}-1 \mathrm{~h}$, (b) Binary- $3 \mathrm{~nm}-1 \mathrm{~h}$ to Binary- $1 \mathrm{~nm}-1 \mathrm{~h}$, (c) Ternary-10 $\mathrm{nm}$ to Ternary- $1 \mathrm{~nm}-1 \mathrm{~h}$, and (d) Ternary- $3 \mathrm{~nm}-1 \mathrm{~h}$ to Ternary-1 nm-1 h.

used as reference cases to estimate errors caused by increasing lower size cutoff and time step.

Different representations of the nucleation mode have a minor effect on globally averaged CCN mode burdens and lifetimes. However, they do affect global-average $J_{10}$ (formation rate of particles greater than $10 \mathrm{~nm}$ from nucleated particles) and the lifetime and burden of ultrafine particles (and thus CN10). When the lower cutoff diameter is raised from $1 \mathrm{~nm}$ to $3 \mathrm{~nm}$ and $10 \mathrm{~nm}$, it leads to systematic biases in $J_{10}$, $\mathrm{CN} 10$ and $\mathrm{CCN}(0.2 \%)$, and these biases are generally much greater with the $10 \mathrm{~nm}$ cutoff. The $\mathrm{CN} 10$ concentrations are biased high, which may be caused by overpredictions in $J_{3}$ or $J_{10}$ by the Kerminen parameterization. The overpredicted $J_{10}$ and $J_{3}$ are likely the result of the instantaneous growth rate assumption rather than missing coagulational growth.

The magnitude of the errors in predicted CN10 concentrations depends strongly on location and what nucleation parameterization is used. Not surprisingly, simple nucleation microphysics leads to larger errors in regions with stronger nucleation and when using the faster ternary nucleation rates. The $10 \mathrm{~nm}$ and $3 \mathrm{~nm}$ boundary simulations show errors in zonally averaged $\mathrm{CN} 10$ predictions up to a factor of 3-5 where high nucleation rates occur. However, the lowermostlayer CN10 deviations are mostly within $50 \%$ except for ternary nucleation with $10 \mathrm{~nm}$ simulations. The change in the
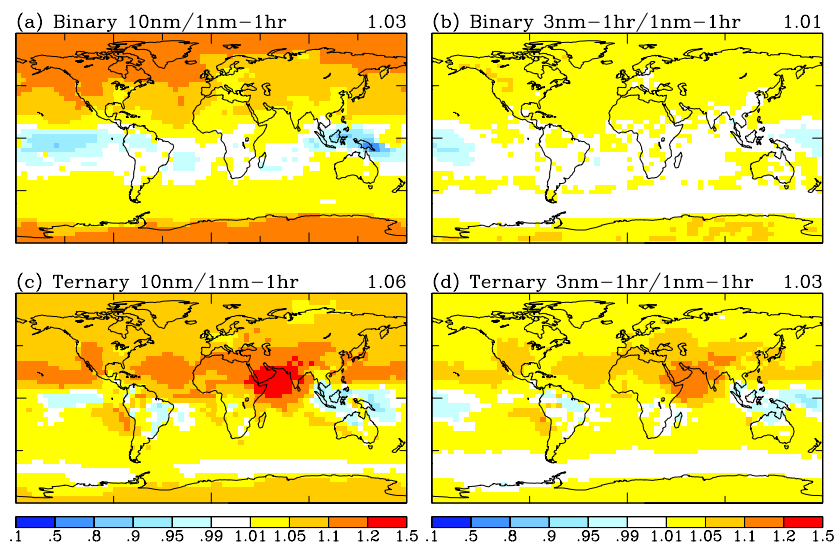

Fig. 9. Same as Fig. 6 but for the following scenarios: (a) Binary$10 \mathrm{~nm}$ to Binary- $1 \mathrm{~nm}-1 \mathrm{~h}$, (b) Binary- $3 \mathrm{~nm}-1 \mathrm{~h}$ to Binary- $1 \mathrm{~nm}-1 \mathrm{~h}$, (c) Ternary-10 nm to Ternary- $1 \mathrm{~nm}-1 \mathrm{~h}$, and (d) Ternary- $3 \mathrm{~nm}-1 \mathrm{~h}$ to Ternary- $1 \mathrm{~nm}-1 \mathrm{~h}$. The value on the top right of each figure is a global average of the ratios displayed in the map.

aerosol microphysics time step from $10 \mathrm{~min}$ to $1 \mathrm{~h}$ has little influence on $\mathrm{CN} 10$ budgets, possibly because of the compensation between the higher $J_{10}$ and the short lifetimes.

The errors in zonal-average $\mathrm{CCN}(0.2 \%)$ with the $3 \mathrm{~nm}$ boundary are mostly within $10 \%$ of the $1 \mathrm{~nm}$ boundary case, while those for the $10 \mathrm{~nm}$ boundary case are larger (within $20 \%$ in most regions). Similarly, the surface-layer $\operatorname{CCN}(0.2 \%)$ from the $3 \mathrm{~nm}$ boundary cases agree with the benchmark $1 \mathrm{~nm}$ model as most regions have only $1 \%$ to $5 \%$ differences, but the $\mathrm{CCN}(0.2 \%)$ from the $10 \mathrm{~nm}$ boundary cases differ by more than $10-20 \%$ in most northern hemispheric areas. We found that this larger deviation is partly attributed to the time step, which is different between the benchmark simulations (i.e., $10 \mathrm{~min}$ ) and the $10 \mathrm{~nm}$ simulations (i.e., $1 \mathrm{~h}$ ). Comparing the simulations with the $1 \mathrm{~h}$ time step, the deviations in the $\mathrm{CCN}(0.2 \%)$ prediction with the $10 \mathrm{~nm}$ boundary are reduced noticeably but still larger than those with the $3 \mathrm{~nm}$ boundary.

This study shows that the representation of nucleation mode in a global aerosol microphysics model has a minor influence on $\mathrm{CCN}(0.2 \%)$ overall, and by extension the aerosol indirect effect, but a more significant impact on CN10 concentrations. For CCN simulations, a model with a lower diameter limit of $10 \mathrm{~nm}$ can be sufficient, but the $3 \mathrm{~nm}$ limit is recommended. Studies focused on CN10 predictions or nucleation will benefit from using a $1 \mathrm{~nm}$ lower size boundary.

Acknowledgements. This study was supported by the Environmental Protection Agency (EPA STAR \#83337401).

Edited by: K. Gierens 


\section{References}

Adams, P. J. and Seinfeld, J. H.: Predicting global aerosol size distributions in general circulation models, J. Geophys. Res.-Atmos., 107, 4370, doi:10.1029/2001JD001010, 2002.

Adams, P. J. and Seinfeld, J. H.: Disproportionate impact of particulate emissions on global cloud condensation nuclei concentrations, Geophys. Res. Lett., 30, 1239, doi:10.1029/2002g1016303, 2003.

Anttila, T., Kerminen, V. M., and Lehtinen, K. E. J.: Parameterizing the formation rate of new particles: The effect of nuclei self-coagulation, J. Aerosol. Sci., 41, 621-636, doi:10.1016/j.jaerosci.2010.04.008, 2010.

Ban-Weiss, G. A., Lunden, M. M., Kirchstetter, T. W., and Harley, R. A.: Size-resolved particle number and volume emission factors for on-road gasoline and diesel motor vehicles, J. Aerosol Sci., Special Issue for the 9th International Conference on Carbonaceous Particles in the Atmosphere, 41, 5-12, 2010.

Clarke, A. D., Owens, S. R., and Zhou, J. C.: An ultrafine seasalt flux from breaking waves: Implications for cloud condensation nuclei in the remote marine atmosphere, J. Geophys. Res.Atmos., 111, D06202, doi:10.1029/2005jd006565, 2006.

Del Genio, A. D. and Yao, M.-S.: Efficient cumulus parameterization for long-term climate studies: The GISS scheme, The Representation of Cumulus Convection in Numerical Models, American Meteorological Society, Boston, Mass., 181-184, 1993.

Del Genio, A. D., Yao, M. S., Kovari, W., and Lo, K. K. W.: A prognostic cloud water parameterization for global climate models, J. Climate, 9, 270-304, 1996.

Ginoux, P., Chin, M., Tegen, I., Prospero, J. M., Holben, B., Dubovik, O., and Lin, S. J.: Sources and distributions of dust aerosols simulated with the GOCART model, J. Geophys. Res.Atmos., 106, 20255-20273, doi:10.1029/2000jd000053, 2001.

Hansen, J., Russell, G., Rind, D., Stone, P., Lacis, A., Lebedeff, S., Ruedy, R., and Travis, L.: Efficient 3-Dimensional GlobalModels for Climate Studies - Model-I and Model-Ii, Mon. Weather Rev., 111, 609-662, 1983.

Jung, J. G., Adams, P. J., and Pandis, S. N.: Simulating the size distribution and chemical composition of ultrafine particles during nucleation events, Atmos. Environ., 40, 2248-2259, 2006.

Jung, J. G., Fountoukis, C., Adams, P. J., and Pandis, S. N.: Simulation of in situ ultrafine particle formation in the eastern United States using PMCAMx-UF, J. Geophys. Res.-Atmos., 115, D03203, doi:10.1029/2009jd012313, 2010.

Jung, J. G., Pandis, S. N., and Adams, P. J.: Evaluation of nucleation theories in a sulfur-rich environment, Aerosol Sci. Technol., 42, 495-504, doi:10.1080/02786820802187085, 2008.

Kerminen, V. M., Anttila, T., Lehtinen, K. E. J., and Kulmala, M.: Parameterization for atmospheric new-particle formation: Application to a system involving sulfuric acid and condensable watersoluble organic vapors, Aerosol Sci. Technol., 38, 1001-1008, 2004a.

Kerminen, V. M., Lehtinen, K. E. J., Anttila, T., and Kulmala, M.: Dynamics of atmospheric nucleation mode particles: a timescale analysis, Tellus Ser. B, 56, 135-146, doi:10.1111/j.16000889.2004.00095.x, 2004b.

Kristjánsson, J. E., Stjern, C. W., Stordal, F., Fjæraa, A. M., Myhre, G., and Jónasson, K.: Cosmic rays, cloud condensation nuclei and clouds - a reassessment using MODIS data, Atmos. Chem. Phys., 8, 7373-7387, doi:10.5194/acp-8-7373-2008, 2008.
Kulmala, M., Vehkamaki, H., Petaja, T., Dal Maso, M., Lauri, A., Kerminen, V. M., Birmili, W., and McMurry, P. H.: Formation and growth rates of ultrafine atmospheric particles: a review of observations, J. Aerosol. Sci., 35, 143-176, 2004.

Lee, Y. H. and Adams, P. J.: Evaluation of aerosol distributions in the GISS-TOMAS global aerosol microphysics model with remote sensing observations, Atmos. Chem. Phys., 10, 2129-2144, doi:10.5194/acp-10-2129-2010, 2010.

Lee, Y. H. and Adams, P. J.: A Fast and Efficient Version of the TwO-Moment Aerosol Sectional (TOMAS) Global Aerosol Microphysics Model, Aerosol Sci. Technol., 46, 678-689, doi:10.1080/02786826.2011.643259, 2012.

Lee, Y. H., Chen, K., and Adams, P. J.: Development of a global model of mineral dust aerosol microphysics, Atmos. Chem. Phys., 9, 2441-2458, doi:10.5194/acp-9-2441-2009, 2009.

Lehtinen, K. E. J., Dal Maso, M., Kulmala, M., and Kerminen, V. M.: Estimating nucleation rates from apparent particle formation rates and vice versa: Revised formulation of the Kerminen-Kulmala equation, J. Aerosol. Sci., 38, 988-994, doi:10.1016/j.jaerosci.2007.06.009, 2007.

Makkonen, R., Asmi, A., Korhonen, H., Kokkola, H., Järvenoja, S., Räisänen, P., Lehtinen, K. E. J., Laaksonen, A., Kerminen, V.M., Järvinen, H., Lohmann, U., Bennartz, R., Feichter, J., and Kulmala, M.: Sensitivity of aerosol concentrations and cloud properties to nucleation and secondary organic distribution in ECHAM5-HAM global circulation model, Atmos. Chem. Phys., 9, 1747-1766, doi:10.5194/acp-9-1747-2009, 2009.

Marticorena, B. and Bergametti, G.: Modeling the atmospheric dust cycle .1. design of a soil-derived dust emission scheme, J. Geophys. Res.-Atmos., 100, 16415-16430, doi:10.1029/95jd00690, 1995.

Merikanto, J., Spracklen, D. V., Mann, G. W., Pickering, S. J., and Carslaw, K. S.: Impact of nucleation on global CCN, Atmos. Chem. Phys., 9, 8601-8616, doi:10.5194/acp-9-8601-2009, 2009.

Napari, I., Noppel, M., Vehkamaki, H., and Kulmala, M.: Parametrization of ternary nucleation rates for H2SO4NH3-H2O vapors, J. Geophys. Res.-Atmos., 107, 4381, doi:10.1029/2002JD002132, 2002.

Pierce, J. R. and Adams, P. J.: Global evaluation of $\mathrm{CCN}$ formation by direct emission of sea salt and growth of ultrafine sea salt, J. Geophys. Res.-Atmos., 111, D06203, doi:10.1029/2005JD006186, 2006.

Pierce, J. R. and Adams, P. J.: A Computationally Efficient Aerosol Nucleation/Condensation Method: Pseudo-Steady-State Sulfuric Acid, Aerosol Sci. Technol., 43, 216-226, 2009a.

Pierce, J. R. and Adams, P. J.: Uncertainty in global CCN concentrations from uncertain aerosol nucleation and primary emission rates, Atmos. Chem. Phys., 9, 1339-1356, doi:10.5194/acp-91339-2009, 2009b.

Pierce, J. R. and Adams, P. J.: Can cosmic rays affect cloud condensation nuclei by altering new particle formation rates?, Geophys. Res. Lett., 36, L09820, doi:10.1029/2009g1037946, 2009c.

Pierce, J. R., Chen, K., and Adams, P. J.: Contribution of primary carbonaceous aerosol to cloud condensation nuclei: processes and uncertainties evaluated with a global aerosol microphysics model, Atmos. Chem. Phys., 7, 5447-5466, doi:10.5194/acp-75447-2007, 2007. 
Prather, M. J.: Numerical Advection by Conservation of 2nd-Order Moments, J. Geophys. Res.-Atmos., 91, 6671-6681, 1986.

Seinfeld, J. H. and Pandis, S. N.: Atmospheric Chemistry and Physics, John Wiley and Sons, New York, 1998.

Snow-Kropla, E. J., Pierce, J. R., Westervelt, D. M., and Trivitayanurak, W.: Cosmic rays, aerosol formation and cloudcondensation nuclei: sensitivities to model uncertainties, Atmos. Chem. Phys., 11, 4001-4013, doi:10.5194/acp-11-4001-2011, 2011.

Spracklen, D. V., Pringle, K. J., Carslaw, K. S., Chipperfield, M. P., and Mann, G. W.: A global off-line model of sizeresolved aerosol microphysics: I. Model development and prediction of aerosol properties, Atmos. Chem. Phys., 5, 22272252, doi:10.5194/acp-5-2227-2005, 2005.

Spracklen, D. V., Carslaw, K. S., Kulmala, M., Kerminen, V. M., Sihto, S. L., Riipinen, I., Merikanto, J., Mann, G. W., Chipperfield, M. P., Wiedensohler, A., Birmili, W., and Lihavainen, H.: Contribution of particle formation to global cloud condensation nuclei concentrations, Geophys. Res. Lett., 35, L06808, doi:10.1029/2007g1033038, 2008.
Trivitayanurak, W., Adams, P. J., Spracklen, D. V., and Carslaw, K. S.: Tropospheric aerosol microphysics simulation with assimilated meteorology: model description and intermodel comparison, Atmos. Chem. Phys., 8, 3149-3168, doi:10.5194/acp-83149-2008, 2008.

Vehkamaki, H., Kulmala, M., Napari, I., Lehtinen, K. E. J., Timmreck, C., Noppel, M., and Laaksonen, A.: An improved parameterization for sulfuric acid-water nucleation rates for tropospheric and stratospheric conditions, J. Geophys. Res.-Atmos., 107, 4622, doi:10.1029/2002JD002184, 2002.

Wang, M. and Penner, J. E.: Aerosol indirect forcing in a global model with particle nucleation, Atmos. Chem. Phys., 9, 239-260, doi:10.5194/acp-9-239-2009, 2009.

Yu, F. and Luo, G.: Simulation of particle size distribution with a global aerosol model: contribution of nucleation to aerosol and CCN number concentrations, Atmos. Chem. Phys., 9, 76917710, doi:10.5194/acp-9-7691-2009, 2009.

Yu, F., Wang, Z., Luo, G., and Turco, R.: Ion-mediated nucleation as an important global source of tropospheric aerosols, Atmos. Chem. Phys., 8, 2537-2554, doi:10.5194/acp-8-2537-2008, 2008. 